\title{
CONCEPTUAL STUDY
}

\section{LATINA TRAJECTORIES TO THE ACADEMY: EARLY EXPERIENCES, EDUCATION POLICIES, AND MENTORING}

Magdalena Martinez, Ph.D.

\begin{abstract}
In this article, l examine three Latinas' early educational experiences, key individuals who shaped their academic paths, their mentorship influences, and the policies and programs that propelled them to complete their doctoral studies. I offer an in-depth analysis, situated in Latinx critical theory (LaCrit) and Chicana feminist theory, of a group of Latinas in the academy, the individuals, education policies, and institutional resources that shaped their trajectories. I discuss two findings that emerged in their early and doctoral education experiences: the role of education policies and programs as experienced by them, and how race and racism intersected with their educational trajectory. I offer two recommendations to improve pathways for Latina doctoral students: continued advocacy for education policies that widen opportunities and implementation of asset-based mentoring programs.
\end{abstract}

Keywords:

Latina Trajectories to the Academy: Early Experiences, Education Policies, and Mentoring

गारे Journal of Transformative Leadership \& Policy Studies 8.1 (2019) 
Latinas are underrepresented in the academy, despite their academic outcomes. Consider, for instance, that Latinas represent almost eight percent of the doctoral degrees (National Center for Education Statistics, 2017) awarded each year, yet they make up two percent of the overall faculty (National Center for Education Statistics, 2018) and less than three percent of executive-level positions in higher education (Kline, 2017). To expand the pathways, we need to examine how Latinas in the academy traverse education pipelines, the role of mentoring, and education policies. Specifically, mentoring during doctoral studies imparts critical information and networks that position future professors and higher education executives (Kamimura-Jimenez \& Gonzalez, 2018; Ramirez, 2017; Turner \& González, 2011). A new understanding of mentorship is needed, one that is emancipatory in practice and can expand the pipeline for new entrants who have historically been excluded from mainstream post-secondary institutions.

As a community of scholars, we need to expand our understanding of the epistemological assumptions of mentorship in higher education. By understanding Latinas' educational trajectory, we can uncover the ways in which mentoring, education programs, and policies aid or hinder the success of women of color in doctoral programs. Critical theories, such as Latinx critical theory and Chicana feminist theory, offer a lens to understand Latinas' experiences and expand our understanding of how they negotiate, develop, and use survival strategies along their career trajectory. Scholars need to examine the cultural, historical, and sociopolitical experiences to understand how they shape or deter Latinas from getting past the doctoral finish line. In this article, I examine three Latinas' early educational 
experiences, key individuals who shaped their academic paths, their mentorship influences, and the programs or policies that propelled them to complete their doctoral studies.

\section{Latinas and Post-secondary Mentoring}

Scholars have identified how undergraduate Latinas come to aspire and see themselves as "graduate school material" through their familial support, sense of community responsibility, participation in institution mentoring programs, and meaningful relationships with faculty or higher education professionals (Luna \& Prieto, 2009; Patton, Renn, Guido, \& Quaye, 2016; Schueths \& Carranza, 2012). Their relationships with faculty and higher education professionals demystify graduate studies while at the same time providing them with the technical knowledge needed to navigate the process (Kamimura-Jimenez \& Gonzalez, 2018; Ramirez, 2017). A genuine interest in the well-being of students is a crucial ingredient for doctoral success. For instance, Rodríguez (2016) examined the personal narratives of Latina doctoral students to understand the key attributes that contributed to successful mentorship relationships during their graduate studies. Key among her findings were that not only is academic support necessary, but more importantly, the personal encouragement they received throughout their graduate studies created a culture of love and inclusiveness where they were allowed to be vulnerable, authentic, and build lifelong relationships with each other and their mentor.

Recently, Acevedo-Gil and Madrigal-Garcia (2018) described a spiritual mentoractivism framework to engage Latino emerging scholars. Like Rodríguez (2016), the author found that congruency needs to exist on their commitment to Latino communities. The 
authors concluded that through relationships with seasoned scholars, Latino students experienced academic validation, an element essential to a scholar's academic identity in the academy. Using the framework of community cultural wealth, Espino (2014) uncovered the ways that Latino doctoral students activated navigational capital, resistant capital, social capital, aspirational capital, and legitimated forms of cultural capital to access graduate school. However, Espino's participants were aware that White-stream (Urrieta \& Méndez Benavidez, 2007) cultural capital was necessary for gaining access to socialization processes and support mechanisms that led to funding and faculty career opportunities. Critical scholars have paved a way to study the experiences of Latina doctoral students' trajectory; however, few studies have examined in-depth the education policies and institutional resources that shaped Latinas' experiences and helped pave the path to the academy. In this article, I offer an in-depth analysis, situated in Latinx critical theory (LaCrit) and Chicana feminist theory, of a group of Latinas in the academy, and the individuals, education policies, and institutional resources that shaped that their trajectories.

\section{Latinx Critical Theory, Chicana Feminist Theory, and Testimonios}

Latinx critical (LatCrit) scholars center their inquiry on the Latinx population in the U.S. and the intersection of race, ethnicity, class and emphasize the cultural, historical, and sociopolitical contexts that shape their experiences (Solórzano \& Yosso, 2001). LatCrit theorists examine the multiple forms of subordination in society, including discrimination based on language, immigration, phenotype, and sexuality. Racism is assumed to be a 
systemic barrier in U.S. society and the aim is to uncover the many embodiments of racial discrimination in societal structures. For instance, LatCrit scholars demonstrate how individuals encounter and resist microaggressions (Solórzano, 1998; Solorzano, Ceja, \& Yosso, 2000). In the United States, microaggressions range from overt to subtle assaults that perpetuate master narratives which harm communities of color and undermine social justice efforts. LatCrit scholars examine individuals and groups, their specific and local experiences with race, ethnicity, gender, community, and forms of resistance and agency (Fernández, 2002; Solórzano \& Delgado Bernal, 2001; Yosso, 2005). Chicana Feminist Theory takes up tenets of LatCrit and incorporates critical components important to women.

Chicana feminist scholars argue sexism, in addition to racism, is an assumed systemic barrier. Further, "issues of immigration, migration, generational status, bilingualism, limited English proficiency, and the contradictions of Catholicism" (Delgado Bernal, 1998, p. 561) are culturally specific experiences that frame women's understanding of the world around them, how they are positioned, and how they respond (Blea, 1992; Delgado Bernal, 1998, 2001, 2002; Espino, 2016; García, 1989). Chicana feminist scholars bring attention to the intersection of multiple oppressive circumstances that shape women's experiences and their resistive practices. Scholars highlight the multiple ways that Latinas are active agents as they interpret their social realities, and strategically organize, oppose, and employ a repertoire of survival strategies grounded in their culture specific experiences (Barajas \& Pierce, 2001; Delgado Bernal, 1998, 2001; Espino, 2016; García, 1989; González, 2002; Hurtado, 2003). Issues of race, ethnicity, gender, class, culture, and power are at the forefront of such analyses, and their specific local histories and contexts provide important analytic frames to interpret individual गाएक 
and group experiences. Chicana feminist scholars use transdisciplinary analytic approaches such as counterstories, and testimonio to accentuate structural inequities and to give voice to individuals affected.

Testimonio is a first-person account that gives voice to Latinas and is an approach that has been employed by scholars to analyze women's multiple identities that informs their experiences (The Latina Feminist Group, 2001; Castillo-Montoya \& Torres-Guzman, 2012; Espino, Muñoz, \& Marquez Kiyama, 2010; Huber, 2009; Reyes \& Curry Rodríguez, 2012). In education research, Huber (2009) has identified central components to testimonios, including that testimonios describe the inequality and inequity people of color confront in their daily lives, are situated in the lived experiences of people of color, and are rooted in the histories and memories of larger communities. Testimonios reveal the ways people are active agents and seek to replace oppressive conditions. Finally, testimonios are a challenge to the apartheid of knowledge that exists in academia (Huber, 2009, p. 645). In higher education research, testimonio approaches have been used to investigate Chicana doctoral experiences (e.g., Espino et al., 2010), female scholars of color (Martinez, Alsandor, Cortez, Welton, \& Chang, 2015), teacher education programs (Cervantes, Flores Carmona, \& Torres Fernández, 2018), undocumented undergraduate students (Romo, Allen, \& Martinez, 2018), and leadership in higher education (Martínez \& Fernández, 2018).

\section{Data Sources and Participants}

The data in this article is part of a larger project that collected the narratives of women of color in higher education and policy-making in a southwestern state. A total of 25 women 
participated, in this article I used three narratives of Latina Ph.D.s who were faculty or executive administrators in higher education. I used purposeful sampling to identify participants who fit a specific gender, ethnic and professional profile that could provide information-rich testimonios. Given the interconnectedness of education communities, the participants knew each other. Each audio interview was transcribed and coded to identify emergent themes (Saldaña, 2015). I feature participants' quotes, rich with details, to provide a deeper understanding of their experiences. I did not design the study to be generalizable; instead, I designed it to shed light on the narratives and experiences of Latinas in the academy, one-by-one. The women, Lorena, Emma and Meli, ${ }^{1}$ were heterosexual and at different states of their careers in the academy.

Lorena was born and raised in southwest and the daughter of Mexican-origin parents. She had worked in higher education for two decades and was a seasoned faculty member, well on her way to obtaining full professorship. She completed her Ph.D. in education in the Southwest. Emma was born and raised in the southwest. Her Mexican immigrant parents were working class and instilled a love for learning. She completed her Ph.D. in education at a selective research university in the Midwest. Emma was a seasoned post-secondary executive who had worked at Predominately White Institutions (PWIs), Hispanic Serving Institutions (HSIs), community colleges and selective universities. Meli was born and raised in the Southwest. Her parents, Mexican immigrants, separated, and she was raised by a single

\footnotetext{
${ }^{1}$ Names are pseudonyms. गIL $\overline{\text { PS }}$ 
mother. Meli completed her Ph.D. in education at a selective university in the Midwest. She was a tenure-track professor at a research university.

Social, cultural, and economic resources shape opportunities. In education spaces, these resources often determine how students traverse and build trajectories. I was interested in understanding the social, cultural, and economic experiences that shaped Latinas' opportunities, the individuals who mentored them, and programs that propelled them to excel. Using testimonios, I considered the ways Latinas storied their experiences to make sense of personal adversity, opportunity, gendered, and racialized events. In the following section, I discuss findings related to their early education and doctoral experiences.

\section{Early Education Experiences: From Political Activism to Access Policies}

I discuss two findings that emerged in their early education experiences: the role of education pipeline policies and programs as experienced by them, and how race and racism intersected with their educational trajectory. The three women came of age on the heels of the 1960s and 1970s civil rights movements. Raised in the Southwest, they were in the thick of the Chicano Movement and they understood there was a direct connection from activism to social policies that expanded educational pathways. For instance, Meli recalled seeing United Farm Workers' picket signs and strikers at her local grocery store discouraging residents from buying grapes. She reflected:

[At the time], I don't think I really understood why Raza were picketing or how it was all connected to my own family. My father was a farmworker, but I knew that there was a group of people who were hurting because of the choices we made in the grocery Jî́ 
stores. Later in life I understood how the "huelgas" were connected to a larger civil rights movement and how many of the education pipeline programs were built on the backs of many of these individuals.

Education pipeline programs or social policies that sought to expand opportunities for previously excluded communities were critical in the women's academic trajectory. However, in their experience education policies and programs were also used to exclude students of color.

\section{Education Policies and Programs}

In elementary school both Emma and Meli were identified as English language learners. However, for Emma, who was raised in a predominantly white community, public school policies were also used to perpetuate inequalities. She described:

My mom told me that they [the elementary school administrators] wanted to put me in special education classes because Spanish was my first language. They wanted to send me across town for special education, where mostly families of color lived. My mom said, 'no' because we literally lived across the street from my neighborhood school. I don't know how my mom did it or talked to them because her English was very limited, but she did. She knew what they were doing, she understood the intent of such a move and how it would affect my academic opportunities in the long run.

Emma's mother, despite her limited English, was determined to advocate for her daughter's educational opportunities and not only call out discretionary practices, but also resisted by refusing to send her "across town" when she could attend her neighborhood school. Similarly, 
Meli's first language was Spanish and she recalled being pulled out of class for English language instruction: "I wasn't pulled out for the gifted program; in fact, none of the kids that were in the gifted programs had a last name that ended with ' $z$ ' like mine." Meli remembered the room where she was taken for English language instruction:

I think it was a supply closest because the room was surrounded by tall metal bookshelves, stacked up to the ceiling with books, unopened boxes, cleaning supplies, and those huge industrial yellow brooms and mops in the corner. There was a high, very small window that didn't really allow sunshine in so it was dark and very cold. In the room, we would sit in a circle with a teacher and white flip chart. The teacher, usually Latino too, would incentivize us to enunciate similar words like "cup" and "cop" correctly by giving us a free ice cream coupon we could use during lunch.

Bearing witness to the physical and racial inequalities at her school, Meli recognized how education policies shaped educational opportunities for Latino students. Moreover, she recounted how her elementary and middle schools were majority Latino students, yet few teachers or administrators spoke Spanish. As a result, Meli was often the official translator for her mother and teachers during teacher-parent conferences. In the absence of culturally connected teachers and administrators and poorly implemented education policies and programs, rather than widen the education pipeline students found themselves demoralized and further segregated within schools. 


\section{Race and Educational Trajectory}

From an early age Meli and Emma witnessed and endured the limitations of education policies intended to widen opportunities. Race was often the factor that shaped how policies were interpreted and implemented. Lorena, a decade older than Meli and Emma, also confronted race and racism in her early years. Because of her light skin, Lorena "passed" and was often a target for "minority" academic and leadership opportunities. Lorena speculated that phenotype played a role in her trajectory:

When I look back at the people who helped support me in high school and in college, I would say - I don't know how else to say it - I had a lot of White women who supported me. I also look back, I'm not dark and I don't have an accent. I wasn't that different than them. But that's not what I saw with peers, you know. Peers who were Puerto Rican or had accents. There were judgements made about them.

By passing, Lorena believed she appeared "less threatening" and more "like them" or the teachers and administrators who often nominated students. Both Emma and Meli had different high school experiences than Lorena. They also understood that race was a key factor in how school teachers and administrators perceived and counseled them. Emma stayed in her neighborhood school and eventually was college-tracked: "I was an honors student, always motivated to do well, not just for my parents but teachers too." One day she recalls her sister, a first-year college student at the time, called and asked her if she was attending college presentations at her high school. "I told her 'no,' and then I told her my counselor said given my PSAT scores I should consider the community college. The next time 
she was in town, she marched down to my school and demanded they change my high school counselor. That changed everything. I ended up getting a one-year scholarship to [the state's land grant university].

Meli was also counseled to attend her community colleges, even though she was an honor student and had the prerequisites to attend her local university. Meli enrolled in her local community college and eventually transferred to her local university. It was at her local university where she met a Chicana professor, as she recounted:

I remember she asked me, "What graduate schools are you considering?" I'd never even considered graduate school, and all of the sudden this woman assumed I was applying and going. It was a transformative moment, someone who I looked up to thought I had what it took to be a graduate student. Although she is in a different discipline, throughout the years we've kept in touch. She has always been a source of support and inspiration.

Access pipeline programs along with key individuals were pivotal in the three women's education trajectory, from the early years to graduate school. For instance, Meli and Emma attended graduate students of color recruitment programs sponsored by elite universities. Through these programs they met faculty and students of color who demystified the application process, introduced them to a cadre of peer mentors and institutional support resources that eventually punctuated and ensured their success in graduate school. 


\section{Flipping the Script in the Academy: Socialization, Mentoring, and Landmines}

The women understood the transformative power of education and were motivated to pursue a Ph.D. to give back to their communities. Once in graduate programs, their doctoral socialization and mentoring experiences varied. As a result of their experiences, they were driven to "flip the script" once they were in positions of influence and decision-making. While in graduate school, their lived experiences and community cultural wealth (Yosso, 2005) was seldom reflected or validated. For instance, Emma remembered her first year of doctoral studies:

No one mentored me, despite the fact that our department had a Latina professor. Her inability to mentor was based on the script that she thought was true to be successful. To be successful did not include mentoring other students that maybe looked like her, had similar experiences to her. The script was not to mentor, it was to produce. Those that she ended up mentoring were mostly white male students who knew how to take advantage of faculty relationships.

After her first year, Emma decided to marry her long-term partner. When she shared the news with her Latina professor, "She told me to my face, I was off her radar. She said, 'You will be married, get pregnant, and you will drop out of the program. I've seen it before.' It was her script, that's what she knew." Emma's experience led her to "figure things out for [her]self or by observing successful advanced doctoral students." The three women were driven to "get past the graduate finish line" as first-generation college students and knew they had to 
identify alternative communities of support to obtain the socialization and mentoring they needed to be successful.

\section{Doctoral Socialization}

Doctoral socialization, a critical component to successful completion (González, 2006), was not something that the women understood at the time, but they observed the ways in which they were on the outside of this socialization. Emma summarized, "I didn't see myself as a colleague of the faculty. I saw white, male colleagues operate like that, but not me. Back then it was like, 'he's so smart', or 'he has something that faculty want', and obviously I didn't. With time, I see that 'yes', maybe that was the case, but it was also that my white, male colleagues knew and understood, 'I'm supposed to get close to you so I can get what I want.' Further, the "script" Emma referenced may also be shaped by the unspoken reality many faculty of color face, particularly at selective universities. Faculty of color face overt and covert racism, are beholden to represent one's race or ethnicity on multiple committees, suffer from negative or unintended consequences of being seen as an affirmative action or target-ofopportunity hire, and feel pressured not to show preference for students who look like them (Garrison-Wade, Diggs, Estrada, \& Galindo, 2012; Gomez, Ocasio, Lachuk, \& Powell, 2015; Trower, 2012; Turner \& González, 2011; Valverde, 2003).

Meli recounted a similar story: "As doctoral students, you heard from other students who were the professors you wanted to work with, and who you should stay away from. As part of my fellowship, I was assigned to a professor, a white male. I was excited to work with him because he was well respected by students. Sadly, during my first semester, he 
announced he was leaving to another university. That left me alone." Meli was then invited by a clinical professor, another white male, to work on a multi-year project. "Although he was not a tenured professor, he welcomed me as part of his team, gave me the space to explore new ideas and research areas of interest and, more importantly, he was genuinely interested in my overall well-being. Even now I visit with him once a year because he continues to be someone I trust."

\section{Academic Comadres}

Meli reflected on her peer mentors, or what she called "academic comadres." There was a strong university-wide graduate students of color organization that created communities of support and encouragement. "I met many of my academic comadres. We would share our challenges, ups and downs, and more importantly strategies for success." Emma explained how institution-sponsored programs made a difference in her doctoral studies as well:

I used the [graduate college] a lot. They would offer seminars. It was through [the graduate college] that I knew I could get statistical help for my dissertation. It was through [the graduate college] that I knew the library had seminars on how to do research. I didn't have a faculty member tell me that. I think it was a colleague of color who told me about the statistical tutoring. I started using it and I realized I could have a standing appointment.

Lorena also shared she had few mentors of color during her doctoral training, but recognized that access policies opened the academy doors for two of the three faculty 
appointments where she was an opportunity hire. While such programs create an entry to the academy pipeline, the institutional language used to classify such efforts may contribute to the backlash experienced by individuals who fill these positions. Well-intended efforts, whether opportunity hires or diversity plans, are the source of microaggressions for the individuals they are intended to serve (Iverson, 2007; Sensoy \& DiAngelo, 2017). The women acknowledged this tension as they passed through the "eye of the needle" (Gándara, 1982) as doctoral students and then as professors and professionals in the academy. In a seminal essay, Uttal (1990) argued that women of color experience an inclusion in the academy without influence. She asserted this form of tokenism perpetuates acts of racism, microaggression, and sexism. The women in the study echoed similar concerns about the academy once they entered as professionals. While the women recognized the importance of education policies that expanded the pipeline, they were concerned about the way the implementation of such programs perpetuated microaggressions in the academy.

\section{Landmines: Microaggressions in the Academy}

In the academy the women navigated racist environments and a culture of microaggressions. "Stepping on landmines" was a metaphor used by Lorena to describe how she matured as a scholar and learned to read the academy's social and political landscape to determine her framing of problems and solutions. All the women shared incidents of microaggressions. Emma, who was a college executive, remembered a colleague confronting her, "Who do you think you are coming in here with all your degrees and giving away our money to Hispanics?" Emma also highlighted the complexities of microaggressions within communities of color:

Jiss 
After testifying at a legislative committee meeting on my college's status in obtaining designation as an $\mathrm{HSI}$, a regent stated on public record that Black students would not feel welcome at an $\mathrm{HSI}$. The regent, who is African-American, added that in his view obtaining HSI designation would be to the detriment of Black students. Although Latinos and Blacks face similar economic, political, social circumstances, the economic and social vulnerability of both groups is fodder for perceived threats. The influx of Latino students in higher education has been viewed by Black community members as further evidence that Blacks will be left with diminishing access, funds, and positions of influence.

Emma's vocal support for equity, students of color, and anti-racist discourse often placed her on the margins, even among people of color. Prior to transitioning to a tenure-track position, Meli also shared her experiences with microaggressions at the highest levels of postsecondary organizations:

During my first year [at the state higher education office], I met with my direct supervisor at least once a month to discuss projects, progress, and leadership philosophies. Her random disparaging comments about Latinos who had worked in office or who were professors initially surprised me but her comments were always couched in the astuteness of academe and her Southern genteel politeness. With the conviction of a veteran academician she would ever so slightly question or dismiss Latinos in the academy and their qualifications. 
The women acknowledged that the severe underrepresentation of other Latinas in similar professional positions made them consider early in their careers whether other paths might be more welcoming to them. Researchers document the ways in which racist practices harm groups of people psychologically and economically (Alvarez, Liang, \& Neville, 2016). In the academy, we have not begun to examine the economic costs of pushing out professors of color and the long-term individual and societal implications.

\section{Reframing Mentoring and Professional Goals}

For this group of women, confronting racist attitudes and microaggressions prompted them to frame their mentoring and professional goals that extended equity and representation. Emma recounted:

As a self-identified Chicana, my experiences as a first-generation American and college student facilitated the construction of a personal and professional agenda to help bring those on the margins into the forefront of higher education. My family's existence from paycheck to paycheck built character, bicultural experiences in an immigrant family engendered compassion and responsiveness, and academic struggles fostered appreciation ... I constantly reminded myself that if my parents could emigrate from Mexico to the United States with limited English skills, no savings and inadequate education, I certainly could navigate the world of academia with a Harvard degree and fellowship in hand.

Similarly, Lorena explained when she transitioned from being a "neutral" professor to speaking up about the harmful effects of racism: 
When I used to teach diversity, I didn't pick a side. I felt I needed to be neutral, but I started to hear teachers say things like, "they don't speak English" and "I don't have time for that" and "that goes to show there are more blacks in prison," blaming the victim. I decided I needed to be really upfront on where I stand on these views. I wanted them to know that if we, as teachers, cannot control our biases then those biases result in discrimination. So, I started to really rethink how I said things. Not holding back, I became more direct, I stepped on some landmines.

As professionals in the academy, they drew from the strength of other women of color, many of whom they had completed doctoral degrees with, met at conferences, or on their campuses. They were motivated to create different approaches to mentoring for their students based on their experiences.

Meli shared, "Although my university strongly discouraged early career professors from over-extending themselves with mentoring responsibilities, I continued to see students, especially doctoral students of color. I would let them know up front that my level of involvement might be limited their first couple of years until I developed a strong footing at the university. They appreciated my honesty." Lorena aspired to mentor and empower students and colleagues by creating opportunities to lead. Lorena elaborated:

As I've gotten older, when I would lead, I would make a lot of decisions because I felt like I was saving a lot of time. But I feel like people need mentoring and they need opportunities to learn how to lead. I guess I've become more of a facilitator leader. And I can do that because I'm older. I wanted control when I was younger, I'm more 
comfortable with being less informed than others now. It's okay if someone is more informed than me.

They agreed that their early education and doctoral experiences shaped how they mentored students at their institutions. Emma reflected on her mentoring philosophy, "I make no assumptions about who they are or what they know. I get to know what their strengths are. I invest in people and use my background in student development to support and challenge them." Further, when it comes to Latino students, "I feel I can be more informal and loving. That is, I show my loving side too because we share a common culture and experiences."

\section{Mentoring Recommendations}

Through testimonios I gained insight into the individuals, institutional resources, and education policies and programs that elevated the women in this article and at times attempted to hold them back. I offer two recommendations. First, at a time when education policies and post-secondary access programs are under assault, we know that many individuals have benefited from these initiatives, including the women in this study. Emma and Meli spoke of policies that were aimed that equalizing opportunities such as English language instruction or special education, yet in their experience policies were also implemented to be roadblocks and, at other times, opportunities. For instance, post-high school, many students of color-including the women in this article-benefited from college access initiatives that demystified higher education and introduced them to individuals and institutional resources for graduate school. In the last decade and a half, however, there have been systematic attempts to eliminate access programs for all underrepresented student 
populations (Chun \& Evans, 2015). Based on the experiences of the women, these programs created important opportunity pathways. Dismantling education policies that underpin access programs will have severe implications on how we mentor doctoral students and the country's ability to diversify the academy. However, as evidenced in the testimonios of the women in this article, not all pipeline education policies are beneficial for students.

Policymakers and institutional leaders should consider the ways in which targeted populations experience policies intended to widen the education pipelines. Moreover, academy mentors and leaders who are committed to equity need to be at the forefront of advocating for culturally relevant education policies across the education pipeline, especially those policies and programs that widen the academic ranks of Latinas.

Second, key individuals shaped the women's academic and career trajectories. From family members, peer-mentors, and professors (both of color and white) validated their familial, aspirational, linguistic, navigational, resistance, and social capital that helped them survive unfamiliar education territory, especially in the academy. For instance, Emma spoke of cultural strengths in the form of her family's immigration narrative that propelled her to continue her doctoral journey. The three women were academically talented and motivated to be successful doctoral students. However, once in the academy their lived experiences were often invalidated. The women were often reminded that White-stream capital was necessary to gain access to the socialization processes and support mechanisms that could lead them to faculty careers. This is where doctoral mentoring programs are especially vital. Leaving doctoral women of color to figure it out for themselves will minimize their completion or opportunities they are likely to pursue beyond their doctoral degree. Doctoral गाt户 
mentoring programs are often designed as a one-size-fits-all, but clearly the lived experiences of students shape how they engage with faculty, peers, and whether they access institutional resources to ensure their completion. Asset-based approaches to mentoring can validate cultural strengths Latinas bring with them to graduate school and enact in their daily lives. An example is the spiritual mentor-activism framework proposed by Acevedo-Gil and MadrigalGarcia (2018). Institutional leaders and faculty should critically examine doctoral mentoring programs to understand whether the embedded assumptions align with the equity goals and women of color lived experiences.

Despite the multiple systemic barriers and roadblocks along the way the women in this article were clearly motivated to create meaningful change through their actions and vocations in higher education. Meli summed it up: "We must move forward and advocate for the policies and programs that opened the door to the academy for us." Today's diverse student population should be tomorrow's academy, leading in new ways to research societal concerns and propose relevant and timely solutions. However, if the academy culture does not change, specifically how Latina doctoral students are mentored, not only will Latinas lose out, but so will our society. 


\section{REFERENCES}

Acevedo-Gil, N., \& Madrigal-Garcia, Y. (2018). Mentoring among Latina/o Scholars: Enacting spiritual activism to navigate academia. American Journal of Education, 124(3), 313344.

Alvarez, A. N., Liang, C. T., \& Neville, H. A. (2016). The cost of racism for people of color: Contextualizing experiences of discrimination. Washington, DC: American Psychological Association.

Barajas, H. L., \& Pierce, J. L. (2001). The significance of race and gender in school success among Latinas and Latinos in college. Gender \& Society, 15(6), 859-878.

Blea, I. I. (1992). La Chicana and the intersection of race, class, and gender. New York, NY: Praeger Publishers.

Castillo-Montoya, M., \& Torres-Guzmán, M. (2012). Thriving in our identity and in the academy: Latina epistemology as a core resource. Harvard Educational Review, 82(4), 540-558.

Cervantes, A., Flores Carmona, J., \& Torres Fernández, I. (2018). Testimonios and liberation psychology as praxis: Informing educators in the borderlands. Journal of Latinos and Education, 1-12.

Chun, E., \& Evans, A. (2015). Affirmative action at a crossroads: Fisher and forward: ASHE Higher Education Report, 41(4).

Delgado Bernal, D. (1998). Using a Chicana feminist epistemology in educational research. Harvard Educational Review, 68(4), 555-583. 
Delgado Bernal, D. (2001). Learning and living pedagogies of the home: The mestiza consciousness of Chicana students. International Journal of Qualitative Studies in Education, 14(5), 623-639.

Delgado Bernal, D. (2002). Critical race theory, Latino critical theory, and critical racedgendered epistemologies: Recognizing students of color as holders and creators of knowledge. Qualitative Inquiry, 8(1), 105-126.

Espino, M. M. (2016). The value of education and educación: Nurturing Mexican American children's educational aspirations to the doctorate. Journal of Latinos and Education, 15(2), 73-90.

Espino, M. M., Muñoz, S. M., \& Marquez Kiyama, J. (2010). Transitioning from doctoral study to the academy: Theorizing trenzas of identity for Latina sister scholars. Qualitative Inquiry, 16(10), 804-818.

Fernández, L. (2002). Telling stories about school: Using critical race and Latino critical theories to document Latina/Latino education and resistance. Qualitative Inquiry, 8(1), $45-65$.

Gándara, P. (1982). Passing through the eye of the needle: High-achieving Chicanas. Hispanic Journal of Behavioral Sciences, 4(2), 167-179.

Garcia, A. M. (1989). The development of Chicana feminist discourse, 1970-1980. Gender \& Society, 3(2), 217-238.

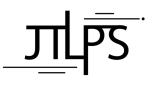


Garrison-Wade, D. F., Diggs, G. A., Estrada, D., \& Galindo, R. (2012). Lift every voice and sing: Faculty of color face the challenges of the tenure track. The Urban Review, 44(1), 90112.

Gomez, M. L., Ocasio, K., Lachuk, A. J., \& Powell, S. N. (2015). The “Battlefield": Life histories of two higher education staff members of color. The Urban Review, 47(4), 676-695.

González, J. C. (2006). Academic socialization experiences of Latina doctoral students: A qualitative understanding of support systems that aid and challenges that hinder the process. Journal of Hispanic Higher Education, 5(4), 347-365.

González, K. P. (2002). Campus culture and the experiences of Chicano students in a predominantly White university. Urban Education, 37(2), 193-218.

Huber, L. P. (2009). Disrupting apartheid of knowledge: Testimonio as methodology in Latina/o critical race research in education. International Journal of Qualitative Studies in Education, 22(6), 639-654.

Hurtado, A. (2003). Voicing Chicana feminisms: Young women speak out on sexuality and identity. New York, NY: NYU Press.

Iverson, S. V. (2007). Camouflaging power and privilege: A critical race analysis of university diversity policies. Educational Administration Quarterly, 43(5), 586-611.

Kamimura-Jimenez, M., \& Gonzalez, J. (2018). Understanding PhD Latinx career outcomes: A case study. Journal of Hispanic Higher Education, 17(2), 148-168. 
Kline, M. (2017). Minorities are paid equitably, but are underrepresented in higher ed leadership. College and University Professional Association for Human Resources. Retrieved from https://www.cupahr.org/blog/minorities-in-higher-ed-administration/

The Latina Feminist Group. (2001). Telling to live: Latina feminist testimonies. Durham: Duke University Press.

Luna, V., \& Prieto, L. (2009). Mentoring affirmations and interventions: A bridge to graduate school for Latina/o students. Journal of Hispanic Higher Education, 8(2), 213-224.

Martinez, M. A., Alsandor, D. J., Cortez, L. J., Welton, A. D., \& Chang, A. (2015). We are stronger together: Reflective testimonios of female scholars of color in a research and writing collective. Reflective Practice, 16(1), 85-95.

Martínez, M., \& Fernández, E. (2018). Moving toward a reconceptualization of Latina/o leadership in higher education. In C. Rodríguez, M. A. Martinez, \& F. Valle (Eds.), Latino educational leadership: Serving Latino communities and preparing Latinx leaders Across the P-20 pipeline (pp. 97-120). Charlotte, NC: Information Age.

National Center for Education Statistics, U.S. Department of Education. (2018). The Condition of Education 2018 (NCES 2018-144). Washington, DC: U.S. Department of Education. Retrieved from https://nces.ed.gov/fastfacts/display.asp?id=61

National Center for Education Statistics. (2017). Doctor's degrees conferred by postsecondary institutions, by race/ethnicity and sex of student: Selected years, 1976-77 through 2015- 
16. Washington, DC: U.S. Department of Education. Retrieved from https://nces.ed.gov/programs/digest/d17/tables/dt17 324.20.asp

Patton, L. D., Renn, K. A., Guido, F. M., \& Quaye, S. J. (2016). Student development in college: Theory, research, and practice. New York, NY: John Wiley \& Sons.

Ramirez, E. (2017). Unequal socialization: Interrogating the Chicano/Latino (a) doctoral education experience. Journal of Diversity in Higher Education, 10(1), 25-38.

Rodríguez, M. A. (2016). Con todo mi corazón: Mentoring Latinas in educational leadership doctoral programs. Association of Mexican American Educators Journal, 10(3), 30-46.

Reyes, K. B., \& Curry Rodríguez, J. E. (2012). Testimonio: Origins, terms, and resources. Equity \& Excellence in Education, 45(3), 525-538.

Romo, E., Allen, T. O., \& Martinez, M. A. (2018). "It Was Kind of a Dream Come True": Undocumented college students' testimonios of cultural wealth in the college choice process. Journal of Hispanic Higher Education, DOI:10.1177/1538192717752816

Saldaña, J. (2015). The coding manual for qualitative researchers. Thousand Oaks, CA: Sage.

Schueths, A. M., \& Carranza, M. A. (2012). Navigating around educational road blocks: Mentoring for Pre-K to 20+ Latino/a students. Latino Studies, 10(4), 566-586.

Sensoy, Ö., \& DiAngelo, R. (2017). “We Are All for Diversity, but...": How faculty hiring committees reproduce Whiteness and practical suggestions for how they can change. Harvard Educational Review, 87(4), 557-580.

가로 
Solórzano, D. G. (1998). Critical race theory, race and gender microaggressions, and the experience of Chicana and Chicano scholars. International journal of qualitative studies in education, 11(1), 121-136.

Solórzano, D. G., \& Delgado Bernal, D. D (2001). Examining transformational resistance through a critical race and LatCrit theory framework Chicana and Chicano students in an urban context. Urban Education, 36(3), 308-342.

Solórzano, D. G., \& Yosso, T. J. (2001). Critical race and LatCrit theory and method: Counterstorytelling. International Journal of Qualitative Studies in Education, 14(4), 471-495.

Solórzano, D., Ceja, M., \& Yosso, T. (2000). Critical race theory, racial microaggressions, and campus racial climate: The experiences of African American college students. Journal of Negro Education, 69(1/2), 60-73.

Trower, C. A. (2012). Success on the tenure track: Five keys to faculty job satisfaction. Baltimore: The John Hopkins University Press.

Turner, C.S.V., \& González, J. C. (2011). Faculty women of color: The critical nexus of race and gender. Journal of Diversity in Higher Education, 4(4), 199-211.

Urrieta Jr, L., \& Méndez Benavidez, L. R. (2007). Community commitment and activist scholarship: Chicana/o professors and the practice of consciousness. Journal of Hispanic Higher Education, 6(3), 222-236.

JIL $\overline{P S}$ 
Uttal, L. (1990). Inclusion without influence: The continuing tokenism of women of color. In G. Anzaldúa (Ed.), Making face, making soul: Creative and critical perspectives by feminists of color (pp. 42-45). San Francisco: Auntie Lute.

Valverde, L. A. (2003). Leaders of color in higher education: Unrecognized triumphs in harsh institutions. Lanham, MD: Rowman \& Littlefield.

Yosso, T. J. (2005). Whose culture has capital? A critical race theory discussion of community cultural wealth. Race Ethnicity and Education, 8(1), 69-91. 